\title{
Evidence that fimbriae of the smut fungus Microbotryum violaceum contain RNA
}

\author{
Martina Celerin, David E. Laudenbach, John B. Bancroft and \\ Alan W. Day
} Author for correspondence: David E. Laudenbach. Tel: + 15196792111 ext. 6485. Fax: +1 5196613935 .
e-mail: LBACH@julian.UWO.CA

Department of Plant Sciences, University of Western Ontario, London, Ontario, N6A 5B7, Canada

\begin{abstract}
The cells of the fungus Microbotryum violaceum produce many long, fine surface hairs that are similar in size and morphology to bacterial pili or fimbriae. These fungal fimbriae are assembled from $74 \mathrm{kDa}$ glycoprotein subunits. We now present evidence that these fimbriae also have a RNA component. Isopycnic centrifugation of fimbriae in caesium chloride produced one band at a density intermediate to that of protein and nucleic acid. The absorbance spectrum of the intact fimbriae was consistent with that of a nucleoprotein. After extraneous RNAs were enzymically removed from the purified fimbrial preparation, disruption of the fibrils resulted in the release of not only the $74 \mathrm{kDa}$ glycoprotein subunits, but also a 30 base single-stranded RNA species. To our knowledge, this is the first example of extracellular RNA as a component of a surface appendage.
\end{abstract}

Keywords: Microbotryum violaceum (Ustilago violacea), extracellular RNA, fimbriae

\section{INTRODUCTION}

Fimbriae, similar to pili of Gram-negative bacteria (Duguid, 1959), but present on the cells of lower eukaryotes, were first described by Poon \& Day (1974) on sporidia of the anther smut fungus, Microbotryum violaceum (Pers.) Deml \& Oberw. [Ustilago violacea (Pers.) Rouss.]. Both mating types of these yeast-like cells produce long $(1-20 \mu \mathrm{m})$, narrow $(7 \mathrm{~nm})$, flexible appendages which extrude from the cell surface (Poon \& Day, 1975). Fimbriae have also been observed on heterozygous diploid sporidia and on promycelia, developed during teliospore germination (Poon \& Day, 1975). Observations of freeze-etched spores indicate that fimbriae arise from the interior surface of the plasma membrane and traverse the cell wall (Poon \& Day, 1975). Previous research has shown that fimbriae are primarily composed of $74 \mathrm{kDa}$ glycoprotein subunits (Gardiner \& Day, 1985) and that the major sugar component is mannose (Castle $e t$ al., 1992). Since their initial discovery, similar fimbriae have also been described on various basidiomycetes, ascomycetes and eukaryotic algae (Calleja, 1987; Crandall et al., 1977; Day et al., 1986; Gardiner et al., 1981, 1982; Hazen \& Hazen, 1993; Rghei et al., 1992; Tokunaga et al., 1990; Xu \& Day, 1992).

Fimbriae are essential for conjugation, may be involved in the development of the conjugation tube (Day, 1976) and are also responsible for transferring sex-specific molecules between opposite mating types prior to conjugation tube growth (Day, 1976; Day \& Poon, 1975). Fimbriae have also been implicated as carriers for the agglutination factors (Calleja, 1987; Crandall et al., 1977; Day, 1976) required for sexual agglutination. Fimbriae may also play an important role in pathogenesis, in particular as adhesion structures responsible for attaching the pathogen to the host (Rghei et al., 1992).

In this report, we provide evidence that intact, native fimbriae of $M$. violaceum contain a nucleic acid component, consisting of single-stranded RNA molecules that are approximately 30 bases in size. To our knowledge, this research represents the first example of the isolation and characterization of a RNA molecule from an extracellular appendage in eukaryotes.

\section{METHODS}

Strains and media. $M$. violaceum, wild-type $\mathrm{a}_{1}$ and $\mathrm{a}_{2}$ strains [UWO-1 $\left(a_{1}\right)$ and UWO-1 $\left(a_{2}\right)$, ATCC 22000 and 22001, respectively; Gardiner et al., 1981] were used in this study. The haploid strains were maintained on Ustilago complete medium (Day \& Jones, 1968) either in liquid culture or on solidified media $(2 \%, w / v$, agar $)$ at $22{ }^{\circ} \mathrm{C}$.

Isolation of crude fimbriae. Exponential-phase haploid spores from well-aerated liquid cultures were harvested by low-speed centrifugation (Sorvall RC-3, HG-4 rotor, $4{ }^{\circ} \mathrm{C}, 10 \mathrm{~min}, 2400 \mathrm{~g}$ ). The pelleted cells were kept on ice, resuspended in distilled water and mechanically defimbriated (Sorvall Omnimixer, 
maximum speed) (Poon \& Day, 1975). The defimbriated cells were pelleted by centrifugation (Sorvall RC-5B, SS-34 rotor, $4{ }^{\circ} \mathrm{C}, 10 \mathrm{~min}, 6500 \mathrm{~g}$ ) and discarded after microscopic examinations confirmed that no cell breakage had taken place. The supernatants containing the crude fimbriae were dialysed against distilled water $\left(4^{\circ} \mathrm{C}\right.$, Spectra/Por membrane, molecular mass cut-off 3500$)$ and concentrated with polyethylene glycol $20 \mathrm{~K}$ (Pohl, 1990).

Purification of crude fimbriae by using caesium chloride isopycnic centrifugation. The density of a caesium chloride solution (approx. $3.6 \mathrm{M}$ ) containing $2.5 \mathrm{mg}$ crude fimbriae $\mathrm{ml}^{-1}$ (by dry weight) was adjusted using a diffractometer (Bausch \& Lomb) to $1.36 \mathrm{~g} \mathrm{~cm}^{-1}$. This solution was subjected to ultracentrifugation (Beckman L8-M ultracentrifuge, Ti40 rotor $\left.15^{\circ} \mathrm{C}, 19 \mathrm{~h}, 120000 \mathrm{~g}\right)$. The caesium chloride gradient: generated were transilluminated with visible light (Fibre Lite, High intensity illuminator $170-\mathrm{D}$ ) and material present in the observed band was collected. The density of the material was measured and the caesium chloride was removed by dialysis.

Electron microscopic observations of fimbriae. A drop of dialysed fimbriae was placed on a formvar-coated $(0.25 \%$, Ladd), carbon-reinforced, 400 mesh copper grid (EMicron) and left for $30 \mathrm{~s}$. Excess fluid was blotted off and, prior to drying, the sample was negatively stained with one drop of $2 \%(\mathrm{w} / \mathrm{v})$ ammonium molybdate, $\mathrm{pH} 7 \cdot 4$ (Poon \& Day, 1974). After $30 \mathrm{~s}$ the excess stain was removed, the grids were air-dried ard viewed with a Phillips EM 200. Material from the caesium chloride band, the top of the gradient, and the pelleted material were all examined in the electron microscope.

Isolation of glycoproteinaceous subunits from polyacrylamide gels. Purified fimbriae were solubilized at $95^{\circ} \mathrm{C}$ for $10 \mathrm{~min}$ in sample buffer $(10 \%, \mathrm{w} / \mathrm{v}$, SDS, $60 \mathrm{mM}$ Tris $/ \mathrm{HCl}$, $\mathrm{pH} 8$, and $5 \%, \mathrm{v} / \mathrm{v}, \beta$-mercaptoethanol). Fimbrial components were separated by electrophoresis on $10 \%$ polyacrylamide gels according to the method of Laemmli (1970). Vertical strips cut from both sides of the gel were stained with $0 \cdot 1 \%$ Coomassie $\mathrm{R} 250$ (in $40 \%, \mathrm{v} / \mathrm{v}$, methanol $/ 10 \%, \mathrm{v} / \mathrm{v}$, acetic acid and destained in the same solvent) and re-aligned with the gel. A horizontal strip, containing the $74 \mathrm{kDa}$ glycoprotein, was cut from the gel and the contents were collected by electro-elution $(100 \mathrm{~V}, 3-5 \mathrm{~h}$, on ice, Little Blue Tank, ISCO) using Laemmli (1970) buffer.

Assessment of purification of glycoprotein components. Glycoproteinaceous material (crude fimbriae, density-gradientpurified fimbriae and eluted subunit components) was solubilized and separated by electrophoresis on $10 \%$ polyacrylamide gels. Gels were stained either with Coomassie R250 or silver (Bio-Rad, Silver Stain Plus; as per manufacturer's instructions).

Isolation of f-RNA. Purified fimbriae were concentrated using unsaturated 2-butanol and one of two methods were employed to isolate f-RNA. In both methods, fimbriae were first subjected to DNase-free (Sambrook et al., 1989) RNase A digestion (Boehringer Mannheim, $5 \mu \mathrm{g}$ fimbriae $\mathrm{ml}^{-1}, 37^{\circ} \mathrm{C}, 30 \mathrm{~min}$ ) prior to $\mathrm{f}-\mathrm{RNA}$ isolation. The single-step method of RNA isolation (Ausubel et al., 1989) using acid guanidinium thiocyanate/phenol/chloroform (AGPC) was used on intact, purified RNase-treated fimbriae. The resultant f-RNA was precipitated in isopropanol and the pellet was dried and resuspended in diethyl pyrocarbonate (DEP)-treated water (Sambrook et al., 1989).

Alternatively, f-RNA was isolated from purified, RNase-treated fimbriae by digestion with Proteinase K (BRL) based on a modification of the method described in Sambrook et al. (1989) (1 U purified fimbriae $\mathrm{ml}^{-1}, 10 \mathrm{mM}$ Tris/ $\mathrm{HCl}, \mathrm{pH} 8,5 \mathrm{mM}$
EDTA, pH $8,0.5 \%$ SDS, $\left.1 \mathrm{mM} \mathrm{CaCl}, 50{ }^{\circ} \mathrm{C}, 3 \mathrm{~h}\right)$. The digestion was terminated with $2 \cdot 2 \mathrm{mM}$ ethylene glycol-bis $(\beta$. aminoethyl ether) $N, N, N^{\prime}, N^{\prime}$-tetraacetic acid (EGTA/HCl, $\mathrm{pH} 8$ ) and repeatedly extracted with phenol/chloroform/isoamyl alcohol $(25: 24: 1$, by vol.). The nucleic acid was precipitated with $0.3 \mathrm{M}$ sodium acetate $(\mathrm{pH} 5.2)$ and 3 vols absolute ethanol. Pellets were dried and resuspended in DEP treated water.

Characterization of f-RNA. f-RNA samples, along with RNA size markers were fully denatured by heating to $95{ }^{\circ} \mathrm{C}$ for $2 \mathrm{~min}$ in $80 \%(\mathrm{v} / \mathrm{v})$ deionized formamide, followed by quick cooling on ice. Analysis by electrophoresis was performed in $1.5 \mathrm{~mm}$ thick, $6 \%(\mathrm{w} / \mathrm{v})$ urea polyacrylamide gels [Hoeffer Mighty Small; $89 \mathrm{mM}$ Tris, $89 \mathrm{mM}$ boric acid, $2 \mathrm{mM}$ EDTA, pH $8(1 \times$ TBE), $150 \mathrm{~V}, 25 \mathrm{~min}$ ]. These gels were stained for $20 \mathrm{~min}$ in ethidium bromide, transilluminated by UV, photographed and then digested with RNase A (Boehringer Mannheim $0.5 \mu \mathrm{g} \mathrm{ml}^{-1}$, $37^{\circ} \mathrm{C}, 1 \mathrm{~h}$ ). The gels were then re-stained in ethidium bromide and photographed a second time. In addition, f-RNA samples were subjected to high $(0.3 \mathrm{M} \mathrm{NaCl})$ or low $(0.03 \mathrm{M} \mathrm{NaCl})$ salt conditions during RNase A digestion $\left(83 \mu \mathrm{g} \mathrm{f-RNA} \mathrm{ml}^{-1}\right.$, $37^{\circ} \mathrm{C}, 30 \mathrm{~min}$ ) to determine strandedness (Bozarth et al., 1971; Goodin et al., 1992).

End-labelling of f-RNA. The $5^{\prime}$ terminal phosphate residues of f-RNAs were hydrolysed using calf intestinal phosphatase (Boehringer Mannheim; Sambrook et al., 1989), and the resultant $5^{\prime}$ hydroxyl groups were end-labelled using T4 polynucleotide kinase (Pharmacia) and $\left[\gamma_{-}{ }^{32} \mathrm{P}\right] \mathrm{ATP}[>6000 \mathrm{Ci}$ $\mathrm{mmol}^{-1}\left(>222 \mathrm{TBq} \mathrm{mmol}^{-1}\right) \mathrm{NEN}$ ] as described by Sambrook et al. (1989). The radiolabelled f-RNAs were separated from the reaction mixture components by filtration through Sephadex G25 columns, followed by precipitation with 3 vols ethanol containing $0.3 \mathrm{M}$ sodium acetate $(\mathrm{pH} 5 \cdot 2)$. The dried pellets were resuspended in DEP-treated water and subjected to urea PAGE (as above). Unlabelled f-RNA was analysed on the same gel. After electrophoretic separation, the resultant gel was dried and the labelled f-RNA band was detected by autoradiography. Its size was confirmed by comparison with the unlabelled $f-$ RNA and with the RNA size markers.

\section{RESULTS AND DISCUSSION}

We have developed a method to isolate purified fimbriae of $M$. violaceum using isopycnic centrifugation in caesium chloride gradients. A single band was generated in the gradient tube, while other material either floated on the surface of the caesium chloride gradient, or was found as a pellet at the bottom of the tube. Electron microscopic examination of the material collected from this band detected only the presence of typical long, $7 \mathrm{~nm}$ diameter fimbriae (Fig. 1). This is in agreement with previous measurements of fimbriae from $M$. violaceum (Poon \& Day, 1974; Gardiner \& Day, 1985). Other material, located at the top of the gradient or as a pellet, was examined and did not contain fimbriae. Analysis of the material from the caesium chloride band (purified fimbriae) by SDS-PAGE using both Coomassie R250 (Fig. 2, lane 3), and silver (Fig. 2, lane 7) staining techniques revealed that the only proteinaceous material present was the $74 \mathrm{kDa}$ subunit. Contrary to this, crude fimbrial preparations contain contaminants that were detectable with Coomassie R250 staining (Fig. 2, lane 5). The $74 \mathrm{kDa}$ subunit is the major constituent of isolated cell surface 


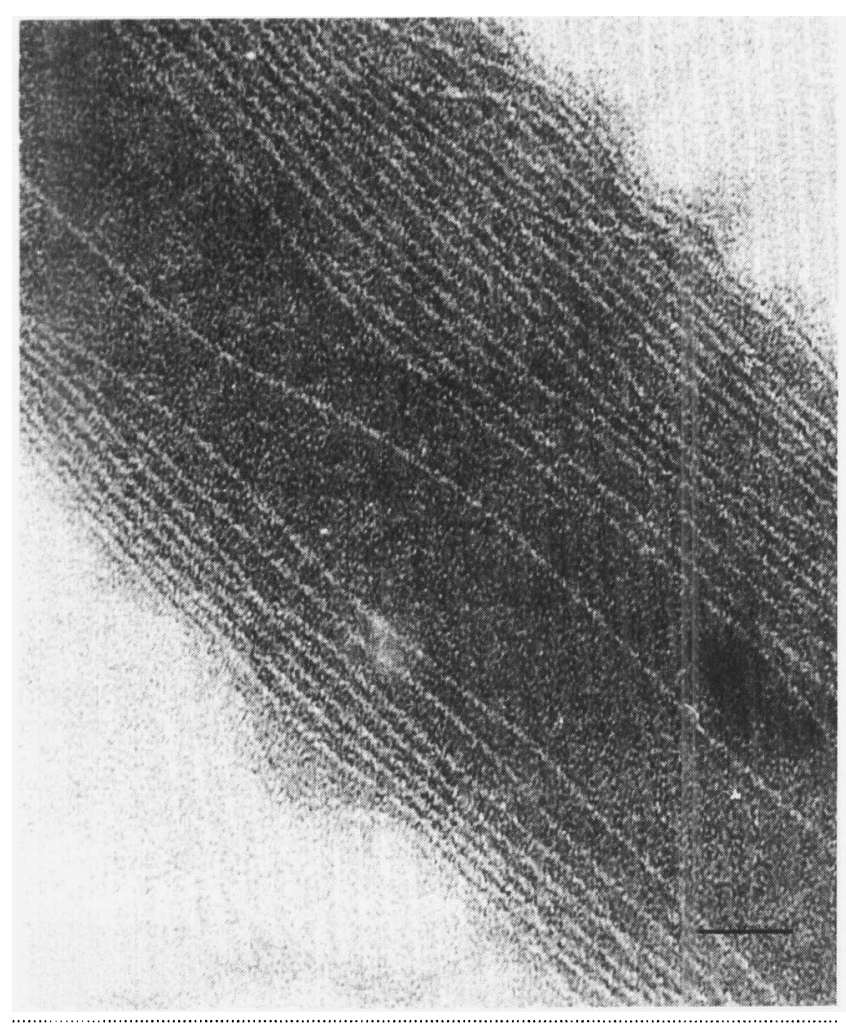

Fig. 1. Electron micrograph of negatively stained $M$. violaceum fimbriae purified by isopycnic caesium chloride gradient centrifugation. Fimbriae found on the surface of haploid spores of $M$. violaceum were $7 \mathrm{~nm}$ in diameter and ranged in length from 1 to $20 \mu \mathrm{m}$. A representative view of the material collected from 10 independent isopycnic gradients is presented. Bar, $0.1 \mu \mathrm{m}$.

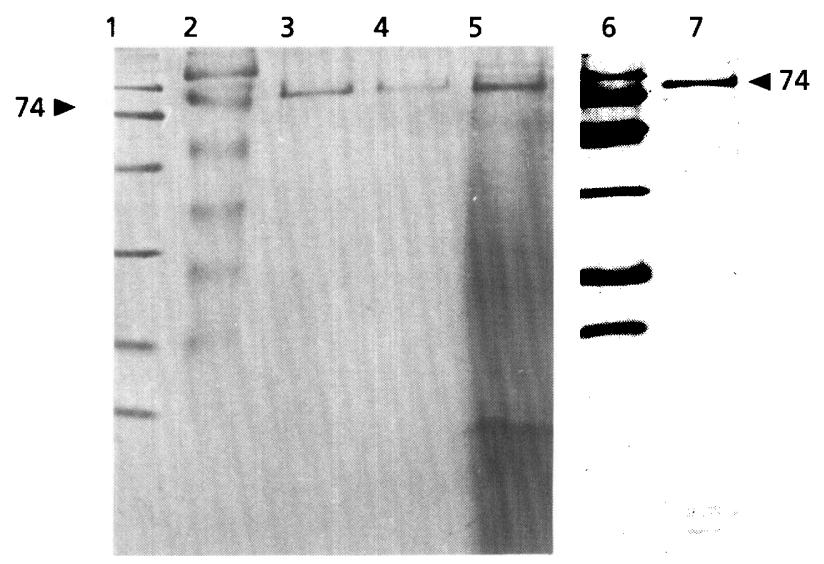

Fig. 2. SDS-PAGE gel stained with Coomassie R250 (lanes 1-5 inclusive) and silver (lanes 6 and 7). Lanes: 1 and 6, protein standards $(94,68,43,30,21$ and $14 \mathrm{kDa}$; Bio-Rad); 2, prestained protein standards $(107,76,52,36.8,27 \cdot 2$ and $19 \mathrm{kDa}$; Bio-Rad); 3 and 7, solubilized fimbriae purified on caesium chloride density gradients; 4, solubilized, eluted glycoprotein subunits of fimbriae; 5 , solubilized crude fimbrial preparation prior to purification. The $74 \mathrm{kDa}$ fimbrial subunit is indicated by an arrowhead.

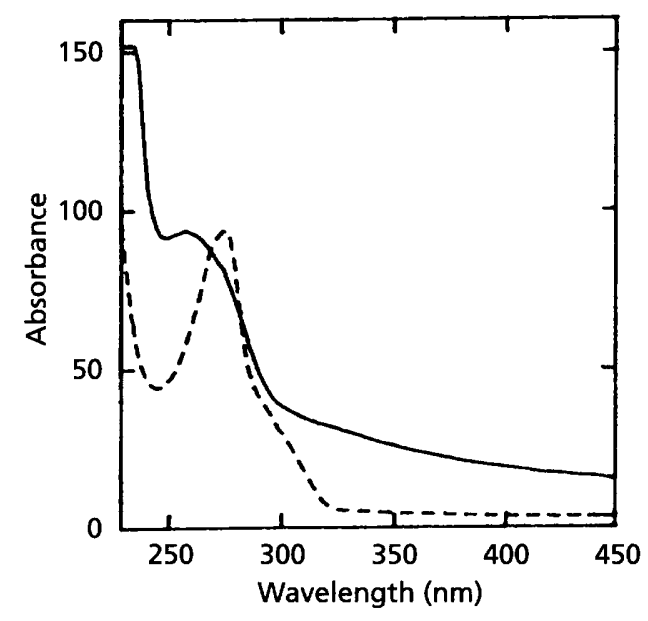

Fig. 3. Spectrophotometric analysis of intact, purified fimbriae from $M$. violaceum and the eluted $74 \mathrm{kDa}$ glycoprotein subunits. Solid line indicates the spectral curve of the intact fimbriae; dashed line shows the spectral curve of the eluted $74 \mathrm{kDa}$ glycoprotein subunits.

material (Gardiner \& Day, 1985). When the subunit glycoproteins were eluted from the polyacrylamide gels and re-separated on a second SDS-PAGE gel (Fig. 2, lane 4), the $74 \mathrm{kDa}$ subunit remained evident and the band appeared similar to that generated by caesium chloride purification.

The density of the purified fimbriae was calculated, based on the observed refractive index (RI) of 1.3683 (mean value of 15 purifications), and using the following equation (Ifft et al., 1961):

$$
\rho^{25^{\circ} \mathrm{C}}=(10 \cdot 8601 \times \mathrm{RI})-13.4974
$$

where $\rho^{25^{\circ} \mathrm{C}}=$ density at $25^{\circ} \mathrm{C}$ of a $\mathrm{CsCl}$ solution.

The calculated density $\left(1.363 \mathrm{~g} \mathrm{~cm}^{-3}\right)$ of fimbriae was used to approximate the percentage composition of fimbriae based on the estimates that in $\mathrm{CsCl}$ solutions, nucleic acids and proteins have densities of $1.70 \mathrm{~g} \mathrm{~cm}^{-3}$ and $1.30 \mathrm{~g} \mathrm{~cm}^{-3}$, respectively. Using the following equation (Freifelder, 1982):

$$
\rho=N(1 \cdot 7)+(1-N)(1 \cdot 3)
$$

where $N=$ percentage of nucleic acid, and $\rho=$ density, it was calculated that fimbriae are structures containing approximately $15 \cdot 7 \%$ nucleic acid.

Spectrophotometric examination of the purified fimbriae (Fig. 3) revealed a curve which resembled that of a nucleoprotein, with an absorption maximum at $258 \mathrm{~nm}$ and a minimum at $249 \mathrm{~nm}$. The $A_{280} / A_{260}$ ratio of purified fimbriae was calculated to be 0.68 . Based on standard curves prepared by Paul (1959) for $A_{280} / A_{260}$ ratios of simple plant viruses, it was estimated that intact fimbriae contain approximately $10-15 \%$ nucleic acid. Collectively, these results implied that the native structure of fimbriae contained a nucleic acid constituent in addition to the protein component. 
A typical spectrum, representative of five separate experiments, of intact purified fimbriae from $M$. violaceum and the eluted, structural $74 \mathrm{kDa}$ subunits is shown in Fig. 3. In contrast to intact, purified fimbriae, the UV absorption spectrum of the eluted $74 \mathrm{kDa}$ glycoprotein subunits showed an absorption maximum at $274 \mathrm{~nm}$ and a minimum at $249 \mathrm{~nm}$. This spectrum is typical of proteins containing $<5 \%$ nucleic acid (Paul, 1959). The pronounced shift in the absorption maximum from $258 \mathrm{~nm}$ (purified fimbriae) to $274 \mathrm{~nm}$ (eluted $74 \mathrm{kDa}$ glycoprotein subunits) indicated that there was a loss of the nucleic acid upon depolymerization of the purified fimbriae into its subunits, thereby indicating that the nucleic acid moiety is probably not covalently linked to the glycoprotein. This suggests that a non-covalent affiliation between the protein and nucleic acid components exists, but its nature and specificity has yet to be determined.

Finally, the nucleic acid component (f-RNA) was isolated from purified, RNase A-treated fimbriae by either disrupting the proteinaceous components using a chaotropic agent (AGPC method) or proteolytic digestion (Proteinase $\mathrm{K}$ method). Intact $\mathrm{f}-\mathrm{RNA}$ was isolated from the fimbriae successfully in seven separate experiments, once using the chaotropic method, and six times using the proteolytic digestion method. Both methods were effective in isolating the nucleic acid component, but the latter resulted in a higher yield. The absorbance spectrum of the final product was consistent with that of a nucleic acid (Fig. 4). The nucleic acid was estimated to contain approximately 30 residues by comparing its migration with that of RNAs of known sizes in a denaturing urea polyacrylamide gel. The nucleic acid present in the gel was made visible by ethidium bromide staining and UV transillumination (Fig. 5, lane 3), and then removed by subjecting the entire gel to digestion with RNase A (Fig. 5, lane 6). Digestion of all RNA polynucleotides present in this gel (and none of the DNA polynucleotides) indicates that the nucleic acid species present in fimbriae is in fact RNA (designated $\mathrm{f}-\mathrm{RNA}$ ). Since digestion occurred in both $0.3 \mathrm{M} \mathrm{NaCl}$ and $0.03 \mathrm{M} \mathrm{NaCl}$ (Fig. 5, lanes 7 and 8), the f-RNA is probably not double-stranded (Bozarth et al., 1971; Goodin et al., 1992). Furthermore, the $5^{\prime}$ end of the f-RNA was successfully labelled using $[\gamma-$ ${ }^{32}$ P]ATP (Fig. 6, lane 3). This entailed enzymic dephosphorylation followed by enzymic re-phosphorylation with a radiolabelled phosphate. The result indicates that the fRNA has a standard $5^{\prime}$ terminal phosphate. To our knowledge, this is the first example of an extracellular RNA polynucleotide that has been localized, isolated and characterized.

The pre-digestions of the purified, intact fimbriae with RNase A prior to chaotropic or proteolytic digestion methods of isolation did not affect $\mathrm{f}-\mathrm{RNA}$ isolation. This indicates that (1) the f-RNA is not a contaminant which co-purifies with fimbriae, and (2) the f-RNA, when present in intact fimbriae, is resistant to RNase digestion. These results suggest that the fimbrial subunits, when present in their native form, must maintain a conformation which effectively protects the f-RNA from external enzymic digestion since an unprotected RNA in the $M$. violaceum

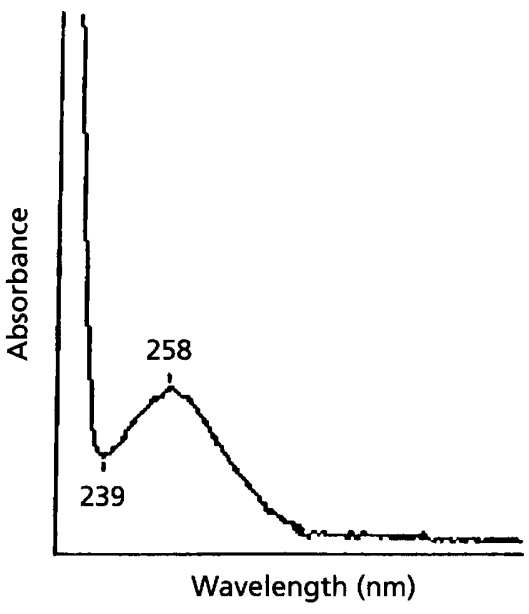

Fig. 4. Spectrophotometric analysis of f-RNA. The absorption maximum is present at $258 \mathrm{~nm}$; the absorption minimum is present at $239 \mathrm{~nm}$.

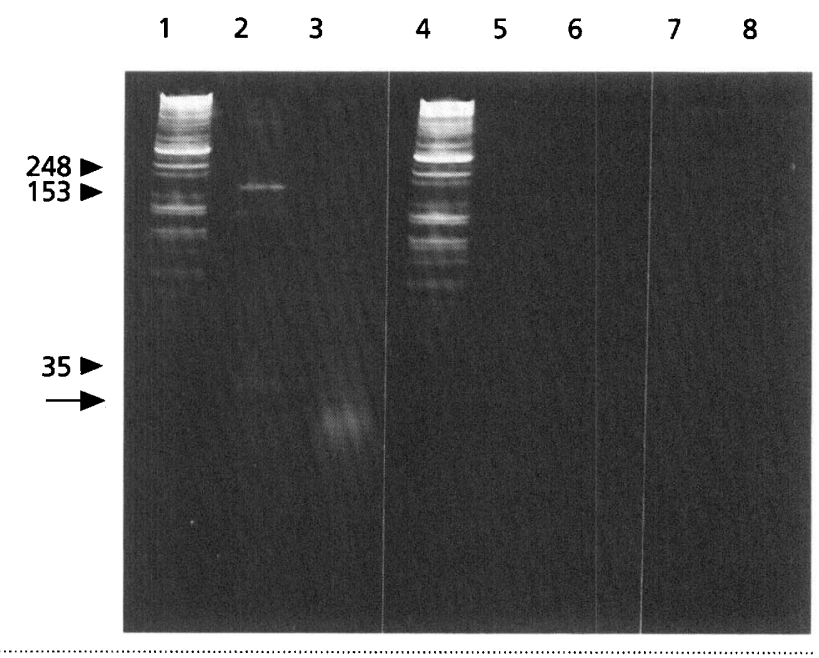

Fig. 5. Detection of $f-R N A$ isolated from the fimbriae of $M$. violaceum, as analysed by $6 \%$ urea PAGE, stained with ethidium bromide and transilluminated by UV. Lanes: 1, partially denatured DNA size markers; 2, molecular RNA size markers $(248,153$ and 35 residues as indicated); 3 , the arrow marks the 30 base single-stranded f-RNA; 4,5 and 6 , same gel as lanes 1-3, respectively, but viewed after digestion with RNase $A ; 7$, RNase $A$ digestion of $f-R N A$ in $0.3 \mathrm{M} \mathrm{NaCl} ; 8$, RNase $A$ digestion of $f$-RNA in $0.03 \mathrm{M} \mathrm{NaCl}$.

environment is highly susceptible to degradation (Donly \& Day, 1984).

Since the ability of the $74 \mathrm{kDa}$ subunits, eluted from SDSpolyacrylamide gels, to reassemble spontaneously into $7 \mathrm{~nm}$ diameter fibrils in the absence of any other component has been documented previously (Gardiner \& Day, 1988), we conclude that the nucleic acid is not required for the assembly of fibrils. This indicates that the f-RNA, at least under some conditions, is not required for the structural integrity of the fibrils. However, calculations indicate that there are a significant number of the 


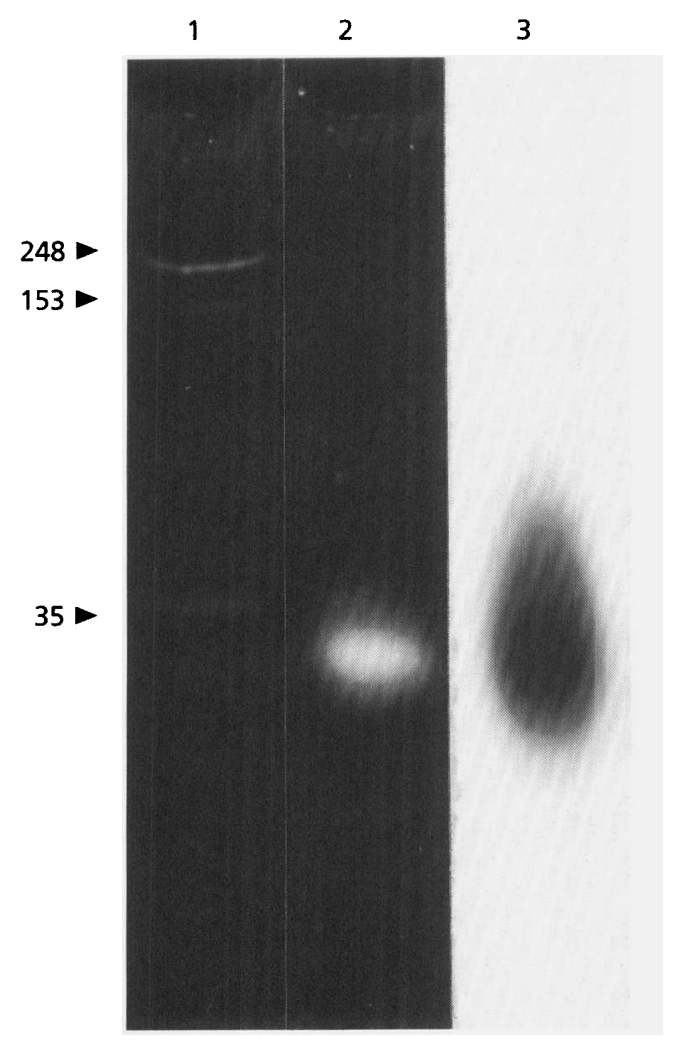

Fig. 6. Analysis of the $5^{\prime}$ terminus of f-RNA. RNAs were subjected to $6 \%$ urea-PAGE, stained with ethidium bromide and transilluminated by UV. Lanes: 1, molecular RNA size markers $(248,153$ and 35 residues as indicated); 2 , unlabelled $f$ RNA; 3 , autoradiograph of $f-R N A ~ 5^{\prime}$ end-labelled with $\gamma^{32} \mathrm{P}$. A total of 75000 c.p.m. was loaded onto the gel. The exposure time was $1 \mathrm{~h}$ at $-80^{\circ} \mathrm{C}$ with an intensifying screen.

f-RNA molecules present in the intact fimbriae (approximately $2.7 \times 10^{3}$ f-RNA molecules in fimbriae of $1 \mu \mathrm{m}$ length).

The importance of fimbriae in intercellular communication, including mating and pathogenesis, is well established. Also, the conserved nature of the glycoproteinaceous subunits which comprise the fimbriae has been demonstrated repeatedly (Benhamou \& Ouellette, 1987; Dav et al., 1986; Gardiner et al., 1981, 1982; Gardiner \& Day, 1988). Thus, the evidence presented here that the extracellular fimbriae found on these lower eukaryotes contain RNA is intriguing and suggests that additional mechanisms must be sought to explain how such organisms interact. Future work on the detailed composition of these extracellular ribonucleoprotein structures in lower eukaryotes may permit new advances in our understanding of cell to cell communication.

\section{ACKNOWLEDGEMENTS}

We thank A. J. Castle for helpful discussion and R. J. Smith for electron microscopic work. RNA size markers were a gift from A. White. This work was supported by grants to A.W.D. and D. E. L. from the Natural Sciences and Engineering Research
Council of Canada (NSERCC). M.C. was the recipient of a NSERCC graduate fellowship.

\section{REFERENCES}

Ausubel, F. M., Brent, R., Kingston, R. E., Moore, D. D., Seidman, J. G., Smith, J. A. \& Struhl, K. (1989). Current Protocols in Molecular Biology, vol. 1. New York: John Wiley \& Sons.

Benhamou, N. \& Ouellette, G. B. (1987). Ultrastructure characterization of an extracellular fibrillar sheath on cells of Ascocalyx abietina, the scleroderris canker agent of conifers. Can J Bot $\mathbf{6 5}$, 154-167.

Bozarth, R. F., Wood, H. A. \& Mandebrot, M. (1971). The Penicillium stolonifer virus complex: two similar double stranded RNA virus-like particles in a single cell. Virology 45, 516-526.

Calleja, G. B. (1987). Cell aggregation. In The Yeasts, vol. 2, 2nd edn, pp. 165-238. Edited by A. H. Rose \& J. S. Harrison. Orlando: Academic Press.

Castle, A. J., Boulianne, R., Xu, J. \& Day, A. W. (1992). Posttranslational modification of fimbrial protein from Ustilago violacea. Can J Microbiol 38, 1144-1149.

Crandall, M., Egel, R. \& MacKay, V. L. (1977). Physiology of mating in three yeasts. Adv Microb Pbysiol 15, 307-398.

Day, A. W. (1976). Communication through fimbriae during conjugation in a fungus. Nature 262, 583-584.

Day, A. W. \& Jones, J. K. (1968). The production and characterization of diploids in Ustilago violacea. Genet Res 11, 63-81.

Day, A. W. \& Poon, N. H. (1975). Fungal fimbriae. II. Their role in conjugation in Ustilago violacea. Can J Microbiol 21, 547-557.

Day, A. W., Gardiner, R. B. \& Brown, L. M. (1986). Extracellular protein fibrils in Chrysochromulina breviturrita (Prymnesiophyceae) and their serological relationship to fungal fimbriae. Arch Microbiol 146, 207-213.

Donly, C. \& Day, A. W. (1984). A survey of extracellular enzymes in the smut fungi. Bot Gaz 145, 483-486.

Duguid, J. P. (1959). Fimbriae and adhesive properties in Klebsiella strains. J Gen Microbiol 21, 271-286.

Freifelder, D. (1982). Sedimentation in density gradients to determine density. In Physical Biochemistry: Applications to Biochemistry and Molecular Biology, 2nd edn, pp. 427-440. New York: W. H. Freeman.

Gardiner, R. B. \& Day, A. W. (1985). Fungal fimbriae. IV. Composition and properties of fimbriae from Ustilago violacea. Exp Mycol 9, 344-350.

Gardiner, R. B. \& Day, A. W. (1988). Surface proteinaceous fibrils (fimbriae) on filamentous fungi. Can J Bot 66, 2474-2484.

Gardiner, R. B., Canton, M. \& Day, A. W. (1981). Fimbrial variation in smuts and heterobasidiomycete fungi. Bot Gaz 142, 147-150.

Gardiner, R. B., Podgorski, C. \& Day, A. W. (1982). Serological studies on the fimbriae of yeasts and yeastlike species. Bot Gaz 143 , 534-541.

Goodin, M. M., Schlagnhaufer, B. \& Romaine, C. P. (1992). Encapsidation of the LaFrance disease-specific double-stranded RNAs in 36-nm isometric virus like particles. Phytopathology 82, 285-290.

Hazen, K. C. \& Hazen, B. W. (1993). Surface hydrophobicity and hydrophilic protein alterations in Candida albicans. FEMS Lett 107, 83-88.

Ifft, J. B., Voet, D. H. \& Vinograd, J. (1961). The determination of density distributions and density gradients in binary solutions at equilibrium in the ultracentrifuge. $J$ Phys Chem 65, 1138-1145. 
Laemmli, U. K. (1970). Cleavage of structural proteins during the assembly of the head of bacteriophage T4. Nature 227, 680-685.

Paul, H. L. (1959). Die bestimmung des nucleinsauregehalts pflanzicher viren mit hilfe einer spektrophotometrischen methode. Z Naturforsch 14, 427-432.

Pohl, T. (1990). Concentration of proteins and removal of solutes. Methods Enzymol 182, 68-83.

Poon, N. H. \& Day, A. W. (1974). 'Fimbriae' in the fungus Ustilago violacea. Nature 250, 648-649.

Poon, N. H. \& Day, A. W. (1975). Fungal fimbriae. I. Structure, origin and synthesis. Can J Microbiol 21, 537-546.

Rghei, N. A., Castle, A. J. \& Manocha, M. S. (1992). Involvement of fimbriae in fungal host-mycoparasite interaction. Physiol Mol Plant Patbol 41, 139-148.

Sambrook, J., Fritsch, E. F. \& Maniatis, T. (1989). Molecular Cloning: A Laboratory Manual, 2nd edn. Cold Spring Harbor, NY: Cold Spring Harbor Laboratory.

Tokunaga, M., Niimi, M., Kusamichi, M. \& Koike, H. (1990). Initial attachment of Candida albicans cells to buccal epithelial cells. Mycopathologia 111, 61-66.

Xu, J. \& Day, A. W. (1992). Multiple forms of fimbriae on the sporidia of corn smut, Ustilago maydis. Int J Plant Sci 153, 531-540.

Received 26 January 1994; revised 9 May 1994; accepted 14 June 1994. 